\title{
COMPONENTES QUÍMICOS DA FARINHA DE BANANA (Musa sp.) OBTIDA POR MEIO DE SECAGEM NATURAL
}

\author{
João Miguel de Moraes Netoํㅜㄹ Luiza Eugênia da M. Rocha Cirne², \\ Juarez Paz Pedroza ${ }^{3}$ e Mozaniel Gomes da Silva ${ }^{4}$
}

\begin{abstract}
RESUMO
Objetivando-se obter farinha de baixo custo e seu possível aproveitamento como alimento adicional para as crianças das creches e escolas da zona rural, banana verde e madura foram submetidas a secagem natural, durante 18 horas. As bananas maduras sofreram secagem adicional em estufa a $60^{\circ} \mathrm{C}$, durante 24 horas; posteriormente, avaliou-se a composição química da farinha por meio das análises de cinzas, carboidratos totais, açúcares redutores e proteínas. A análise estatística revelou que, para os percentuais de açúcares redutores e carboidratos totais, ocorreram diferenças significativas entre os tratamentos, enquanto para os demais percentuais não se evidenciou tal efeito.
\end{abstract}

Palavras-chave: secagem, farinha de banana, componentes químicos

\section{CHEMICAL COMPONENTS OF THE BANANA (Musa sp.) FLOUR PRODUCED BY DRYING}

\begin{abstract}
With the purpose of producing a low cost flour, looking for its exploitation as a supplementary food for the school and nursery children in the rural area, unripe and ripe banana were submitted to a sun-drying for an 18 hours period. The ripe bananas had an additional drying in an oven adjusted at $60^{\circ} \mathrm{C}$ for 24 hours. Later on, the chemical composition of the flour was evaluated by the ash, total carbohydrate, reduced sugar and protein analyses. The statistical analysis showed that for the percentage of reduced sugars and carbohydrates significant differences occurred between the treatments, while for the other percentages such effects were not observed.
\end{abstract}

Key words: drying, banana flour, chemical components

\section{INTRODUÇÃO}

Dentre as frutas tropicais destaca-se, desde os tempos mais remotos, a banana, como uma das mais ricas fontes de alimento energético (ETENE, 1966). Citam-se as seguintes vantagens, entre outras, que evidenciam o valor desta fruta:

- cultivo simples e vida econômica, que oscila de cinco a dez anos
- colheita após o primeiro ano

- colheita permanente durante $\mathrm{o}$ ano, sem grandes diferenças de volume

- fruta bastante nutritiva e de paladar agradável.

Segundo FAO (1986) o Brasil é o maior produtor mundial de banana, com aproximadamente $18 \%$ da produção, sendo que, pelas dificuldades apresentadas e devido à sua perecibilidade, a exportação 'in natura' se torna bastante difícil. A industrialização é, sem dúvida, uma grande alternativa para o aproveitamento

\footnotetext{
${ }^{1}$ Prof. Assistente, Mestre, DEAg, CCT, UFPB, CP 10.087, fone: (083) 310-1194, fax: 310-1185. E-mail: moraes@deag.ufpb.br CEP 58.109-970 - Campina Grande. PB

${ }^{2}$ Prof. Assistente, Mestre, DEAg, CCT, UFPB

${ }^{3}$ Prof. Assistente, Mestre, DEAg, CCT, UFPB

${ }^{4}$ Prof. Assistente, Mestre, DEAg, CCT, UFPB
} 
integral da banana, podendo ser ela utilizada como compotas, banana-passa, farinha, licor, geléia etc.

A casca da banana representa cerca de 47 a $50 \%$ em peso da fruta madura mas, até o presente momento, não têm tido aplicações de ordem industrial, sendo esporadicamente utilizada, de forma direta, na alimentação animal, porém em escala reduzida (Travaglini et al.,1993).

Ante as possibilidades de industrialização, a farinha de banana já mostrou ser um empreendimento bastante promissor, podendo ser utilizada em panificação, produtos dietéticos, alimentos infantis e até como ração animal.

Loures et al. (1990) obtiveram farinha de boa qualidade por meio de secagem em secador de ar circulante a $50^{\circ} \mathrm{C}$, durante dezesseis horas, e moagem em moinho de faca. A farinha foi adicionada à farinha de trigo e concluiu-se que com até $20 \%$ de farinha de banana os pães foram considerados aceitáveis.

Este trabalho tem, portanto, o objetivo de obter farinha de banana de baixo custo, visando a um possível aproveitamento como alimento adicional para crianças, utilizando-se secagem natural para banana verde e madura e, posteriormente, avaliandose a composição química da farinha por meio das análises de cinzas, carboidratos totais, açúcares redutores e proteínas.

\section{MATERIAL E MÉTODOS}

A farinha de banana foi produzida utilizando-se a cultivar (Musa sapientum) variedade prata, assim conhecida na região e proveniente da EMPASA de Campina Grande, PB. A banana verde e madura foi despencada e cuidadosamente separada para ser lavada em água corrente clorada; logo após, foi coberta com papel absorvente para retirada do excesso de água e cortada com faca, em rodelas de aproximadamente $2 \mathrm{~cm}$ para, em seguida, ser exposta ao sol em bandejas metálicas de $60 \times 60 \mathrm{~cm}$. A secagem ao sol durou exatamente 18 horas, tempo suficiente para a banana verde atingir o ponto de farinha; a banana madura sofreu uma secagem adicional em estufa a $60^{\circ} \mathrm{C}$, por 24 horas e a massa obtida após a secagem foi moída em moinho de faca e encaminhada para análise, acondicionada em sacos de plástico.

Amostras de farinha de banana verde e madura foram submetidas às análises descritas a seguir:

- os carboidratos totais e os açúcares redutores foram determinados por meio do método colorimético proposto por Somogyi (1990);

- o resíduo mineral fixo, ou cinzas, foi determinado segundo metodologia proposta pelo ITAL (1990).

- os compostos nitrogenados foram determinados pelo método proposto pelo Instituto Adolfo Lutz (1985) cujas proteínas foram estimadas multiplicando-se pelo fator 6.25.

As normais climatológicas locais durante o período de condução do experimento (novembro/93) segundo o boletim Informações Climatológicas do Departamento de Ciências Atmosféricas do CCT/UFPB, foram as seguintes:

- Insolação média mensal

- Radiação solar global

- Temperatura máxima

- Temperatura mínima

- Temperatura média mensal

- Umidade relativa do ar

8,5 horas
490 cal.cm
$30^{\circ} \mathrm{C}$
$19^{\circ} \mathrm{C}$
$24^{\circ} \mathrm{C}$
$73 \%$

Os dados foram obtidos de acordo com delineamento estatístico inteiramente casualizado, com dois tratamentos (banana verde e maduro) e três repetições.

\section{RESULTADOS E DISCUSSÃO}

Depois de 18 horas de secagem ao sol obteve-se a média de $13,8 \%$ de umidade para banana madura e de $7,2 \%$ para banana verde.

Tem-se a Tabela 1, a seguir, a qual, contém os valores médios de umidade obtidos ao longo dos dias de secagem ao sol.

Tabela 1. Valor médio da umidade (U\%) da farinha de banana verde e madura

\begin{tabular}{lccccr}
\hline Datas de secagem & $23 / 01$ & $24 / 01$ & $25 / 05$ & $26 / 01$ & $29 / 01$ \\
\hline U\% Banana madura & 70,1 & 54,0 & 50,9 & 29,7 & 13,8 \\
U\% Banana verde & 73,5 & 57,8 & 50,1 & 22,4 & 7,2 \\
\hline
\end{tabular}

Como se observa nos dados apresentados na Tabela 1 , a banana madura continua com teor de umidade acima do ideal, para obtenção da farinha, mesmo depois de 18 horas de secagem ao sol, o que não ocorre com a banana verde, que pode ser levada diretamente para moagem. Para que a banana madura obtivesse o ponto de farinha foi necessário uma secagem adicional em estufa a $60^{\circ} \mathrm{C}$, durante 24 horas.

É bastante difícil secar banana madura até o ponto necessário ( $10 \%$ de umidade ou menos) com qualquer processo natural; a razão é que o substrato vai melar se a banana for madura ou ficar pelo menos com mais de $12 \%$ de água, em estado mole, flexível e sujeito a alterações, inclusive a mofo; outrossim, bananas imaturas apresentam um tipo de farinha bem mais fácil de secar (ETENE, 1966).

\section{Coloração}

Ainda com relação às farinhas, observou-se que a proveniente das bananas verdes apresentou coloração bem mais clara e, consequentemente, mais apresentável que a das bananas maduras, o que está de acordo com os resultados encontrados pelo Departamento de Estudos Econômicos do Nordeste (ETENE, 1996).

\section{Carboidratos totais e açúcares redutores}

As Tabelas 2 e 3 apresentam as análises de variância dos percentuais de carboidratos totais e açúcares redutores das farinhas de banana verde e madura, obtidas no processo de secagem natural.

Tabela 2. Análise de variância dos percentuais de açúcares redutores das farinhas de banana verde e madura

\begin{tabular}{lcccc}
\hline Fonte de variação & G.L. & S.Q. & Q.M. & F \\
\hline Tratamento & 1 & 10,988 & 10,988 & $29,38^{* * *}$ \\
Resíduo & 4 & 1,496 & 0,374 & \\
Total & 5 & 12,485 & 2,871 & \\
\hline
\end{tabular}

"Significativo ao nível de $1 \%$ de probabilidade

Tabela 3. Análise de variância dos percentuais de carboidratos totais das farinhas de banana verde e madura

\begin{tabular}{lcccc}
\hline Fonte de variação & G.L. & S.Q. & Q.M. & F \\
\hline Tratamento & 1 & 22,854 & 22,854 & $21,20^{* *}$ \\
Resíduo & 4 & 1,109 & 0,277 & \\
Total & 5 & 23,964 & 5,070 & \\
\hline
\end{tabular}

"Significativo ao $1 \%$ de probabilidade 
Os dados apresentados nas Tabelas 2 e 3 revelam que o teste de médias é significativo ao nível de $1 \%$ de probabilidade, ou seja, os percentuais de carboidrato totais e açúcares redutores diferem entre a banana verde e madura. Durante o amadurecimento dos frutos há diminuição do teor de polissacarídeos, com conseqüente aumento dos teores de açúcares redutores, decréscimo no teor de taninos, tornando os frutos menos adstringentes e com mais compostos voláteis responsáveis pelo odor e gosto característico do fruto maduro (Carvalho \& Cardoso, 1980).

A Tabela 4 apresenta os dados da análise de variância dos percentuais de cinza das farinhas de banana verde e madura obtidas no processo de secagem natural.

Tabela 4. Análise de variância dos percentuais de cinza das farinhas de banana verde e madura

\begin{tabular}{lcccc}
\hline Fonte de variação & G.L. & S.Q. & Q.M. & F \\
\hline Tratamento & 1 & 0,06833 & 0,06833 & $0,00366^{(n s)}$ \\
Resíduo & 4 & 0,7457 & 0,18642 & \\
Total & 5 & 0,1429 & & \\
\hline
\end{tabular}

ns - Não Significativo a 5\% de probabilidade

Os dados apresentados na Tabela 4 revelam que o teste de médias não é significativo ao nível de 5\% de probabilidade, ou seja, os percentuais de cinza não diferem significativamente entre as farinhas de banana verde e madura. As cinzas obtidas não correspondem necessariamente à soma das substâncias minerais presentes no alimento, devido às perdas por volatilização e interação entre os seus compostos. Travaglini et al.(1993) estudando a composição da banana-passa verificou um teor de ferro relativamente baixo, porém o mesmo se encontra $100 \%$ disponível e assimilável, uma vez que apresenta teor de cobre suficiente para favorecer a assimilação de ferro.

Os valores médios obtidos para as cinzas nas farinhas de banana verde e madura foram 4,14 e 4,35, respectivamente, e se mostraram superiores aos valores encontrados por Wrancky \& Kervegant, citados por Travaglini et al. (1993), ao estudar os constituintes da banana- passa.

A Tabela 5 apresenta os dados da análise de variância dos percentuais de proteína das farinhas de banana verde e madura, obtidas no processo de secagem natural.

Tabela 5. Análises de variância dos percentuais de proteína das farinhas de banana verde e madura

\begin{tabular}{lcccc}
\hline Fonte de variação & G.L. & S.Q. & Q.M. & F \\
\hline Tratamento & 1 & 0,00881 & 0,00881 & $1,699^{(\mathrm{ns})}$ \\
Resíduo & 4 & 0,0209 & 0,0052 & \\
Total & 5 & 0,002971 & 0,00059 & \\
\hline
\end{tabular}

ns - Não Significativo ao 5\% de probabilidade

Analisando-se os dados apresentados na Tabela 5, verificase que as variações ocorridas nos percentuais de proteína não decorrem da existência de efeito significativo para o fator tratamento, ou seja, este percentual não apresenta diferença significativa entre as farinhas de banana verde e madura.

A banana apresenta baixo teor de proteína e gordura; entretanto, o teor de proteína da casca de banana é cerca de $8 \%$ no produto seco, porém se salienta o seu baixo valor biológico, quando comparado, por exemplo, com a proteína dos cereais (Travaglini et al. 1993).

Os valores médios das proteínas das farinhas de banana verde e madura foram $3,2 \%$ e 3,3\%, respectivamente, valores também encontrados por Travaglini et al. (1993) em estudos com polpa de banana madura.

\section{CONCLUSÕES}

1. A secagem natural da banana madura até o ponto ideal de umidade para obtenção de farinha, mostrou-se impraticável, evidenciando a necessidade de secagem artificial adicional.

2. Nas condições experimentais adotadas foram necessárias 18 horas de secagem para que as bananas verdes atingissem o teor de umidade ideal para obtenção de farinha.

3. As análises químicas comprovaram a riqueza da farinha em carboidratos totais e açúcares redutores, evidenciando a importância de sua utilização como fonte de alimento humano e animal.

4. A qualidade da farinha da banana verde, com relação ao aspecto e coloração, mostrou-se mais apresentável que a da banana madura, o que, possivelmente, lhe possibilitará maior aceitação por parte dos consumidores.

\section{AGRADECIMENTOS}

Ao Laboratório de Controle de Qualidade, Pesquisa e Desenvolvimento da Refinaria de Milho do Brasil por ter, gentilmente, efetuado as análises de proteína.

\section{REFERÊNCIAS BIBLIOGRÁFICAS}

CARVALHO. V.D. de; CARDOSO, D.A.M. Industrialização da banana. EPAMIG - Informe Agropecuário, Belo Horizonte v. 6, n 63, 1980.

ETENE, Departamento de Estudos Econômicos do Nordeste. Farinha de banana: Resultados de pesquisas tecnológicas. Fortaleza, CE, 1996. 45p.

FAO. Food and Agriculture Organization. Production yearbook. Roma: FAO, 1986. 306p.

INSTITUTO ADOLFO LUTZ. Normas analíticas-métodos químicos e físicos de análises de alimentos. V. $1,3^{\mathrm{a}} \mathrm{Ed}$.. São Paulo, SP: 1985.

ITAL. Instituto de Tecnologia de Alimentos. Manual Técnico. Campinas, SP: ITAL 1990. 120p.

LOURES. A.; COELHO, D.T.; CRUZ, R.; LUCY, C. Obtenção, caracterização e utilização da farinha de banana (Musa sp.) em panificação. Ciência Tecnologia_Alimento SP, v. 10, $\mathrm{n}^{\circ}$ 1, p. 51-57, 1990.

SOMOGYI, M. Notes on sugar determination. Journal Biological Chemistry, $n^{\circ}$ 200, p. 145-154, 1990.

TRAVAGLINI, D.A.; NETO, M.P.; BLEINROTH, E.W.; LEITÃO, M.F.F. Banana-passa: princípios de secagem, conservação e produção industrial. Campinas, SP: Instituto de Tecnologia de Alimentos - ITAL, 1993. 73p. (Manual Técnico $\mathrm{n}^{\circ} 12$ ) 